\title{
Synthesis and characterization of fully biobased polyesters with tunable branched architectures $\dagger$
}

\author{
Nejib Kasmi, ${ }^{a}$ Catherine Pinel, ${ }^{\mathrm{b}}$ Denilson Da Silva Perez, ${ }^{\mathrm{c}}$ Reiner Dieden (D) ${ }^{\mathrm{a}}$ and \\ Youssef Habibi (D) *a
}

\begin{abstract}
A series of sugar-derived triols and biobased diacids were combined to prepare fully biobased branched polyesters with different structural features by melt polycondensation. By applying the BiMolecular Non-Linear Polymerization methodology (BMNLP), the molar ratio of diacid/ triols was varied to access branched polyesters bearing either hydroxyl or carboxyl moieties as end groups. The structural features of the resulting polymers were scrutinized by ${ }^{1} \mathrm{H} /{ }^{13} \mathrm{C}$ NMR, and FT-IR spectroscopies, whereas DSC and TGA were used to investigate their thermal properties. The structure-property relationship of the synthesized polyesters was correlated to the structure of the triols and diacids and their molar ratio. Both prepared carboxyl-ended and hydroxyl-ended branched polyesters were amorphous with relatively low glass transition temperatures ranging between -57 and $-18{ }^{\circ} \mathrm{C}$ for hydroxyl terminated polyesters while for carboxyl terminated ones, they oscillate between -37 and $19{ }^{\circ} \mathrm{C}$. All these polyesters exhibit good heat resis-tance with onset degradation temperature $T_{\mathrm{d}, 5 \%}$ ranging from 180 to $268{ }^{\circ} \mathrm{C}$ and from 168 to $236{ }^{\circ} \mathrm{C}$ for $\mathrm{COOH}$ - and $\mathrm{OH}$-end groups-bearing polymers series, respectively. The structural features and properties of the resulting branched fully biobased polyesters make them not only potential candidates for a wide range of applications but also as intermediate substrates for further chemical modifications and/or chain extension to access a wide range of functional (co)polymer materials.
\end{abstract}

\section{Introduction}

Bio-based polymers have witnessed a spiralling growth of interest, shaping thus the future of sustainable plastics as one of the most interesting domains in materials science. ${ }^{1-5}$ The development of this type of eco-friendly polymers will not only alleviate our overwhelming reliance on fossil feedstock, but providing also new materials with a significantly better environmental footprint and enhanced performances with respect to those of their petroleum-based counterparts. ${ }^{6-8}$ Among the different classes of polymers, polyesters are the most rapidly growing with the largest market share of bioplastics. ${ }^{9}$ Linear biobased polyesters, either aliphatic or aromatic, are one of the most actively investigated polymer families. This stems primarily from their interesting properties, transparency, reusability and low cost and they have received a tremen-

\footnotetext{
${ }^{a}$ Department of Materials Research and Technology (MRT), Luxembourg Institute of Science and Technology (LIST), 5 avenue des Hauts-Fourneaux, L-4362 Esch-surAlzette, Luxembourg. E-mail: Youssef.Habibi@list.lu

${ }^{b}$ University Lyon, University Claude Bernard, CNRS, IRCELYON, UM5256, 2 Avenue Albert Einstein, 69626 Villeurbanne, France

${ }^{c}$ Institut FCBA, InTechFibres, 38044 Grenoble, France

$\dagger$ Electronic supplementary information (ESI) available. See DOI: 10.1039/ d0py01512a
}

dous level of interest. ${ }^{10,11}$ A distinguished bunch of biobased polyesters such as poly(L-lactic acid) (PLA), furanoate co/ polyesters, ${ }^{12-21}$ poly(alkylene succinates) ${ }^{22-28}$ and others, such as poly(3-hydroxy butyrates) (PHA), poly(hydroxyl alkanoate)s (PHAs), are commercially available nowadays in various forms witnessing for the future importance of such polymers. ${ }^{29-31}$

(Hyper)-branched polyesters are a class of polymers that is attracting a tremendous level of interest due to their unique three-dimensional molecular structures that can be easily tuned by controlling the branching degree as well as their functional end groups endowing them with a wide range properties. ${ }^{32}$ These properties make them promising candidates for several applications such as supports for catalysts, and viscosity modifiers, as well as targeted drug delivery systems. ${ }^{33,34}$ As relevant example, an interesting recent review highlighting the synthetic procedures of polyglycerol hyperbranched polyesters as well as their applications in pharmaceutical technology and in biomedical applications was published by Boccaccini and Bikiaris groups. ${ }^{35}$ In this context along with the relatively good availability of suitable building blocks derived from renewable resources, particular interest has been devoted to access biobased branched-type polyesters. ${ }^{34,36-43}$ Such interest is expected to further increase under the developments currently made in the production of building blocks that will bring forth new entirely biomass-derived monomers (triols, and diacids) 
through optimized processes. ${ }^{44}$ This is due to the attractive features that can be easily tuned by controlling their functionality from hydroxyl to carboxylic end groups leading to very distinct properties and thus multiple uses. ${ }^{45-47}$

Hemicelluloses constitute an important feedstock for the preparation of sustainable building blocks including diols, polyols, diacids, diamines etc., through catalytic and biotechnological pathways. ${ }^{48,49}$ Polyols are the main building blocks necessary; 1,2,6-hexanetriol is such a biobased triol, which readily prepared by hydrogenolytic ring-opening of 5-hydroxymethylfurfural (HMF) which can be in turn prepared through sequential hydrolysis, isomerization, and dehydration of sugars derived from hemicellulose. ${ }^{50}$ 1,2,4-Butanetriol, another eco-friendly valuable polyol extensively exploited in polyurethane foams production, is being obtained from xylose. ${ }^{51}$ A major breakthrough involving a catalytic conversion of lignocellulosic biomass, corn stover, into adipic acid has been recently reported by Han. ${ }^{52}$ In this green process, hemicellulose and cellulose derived $\delta$-valerolactone was used as solvent and an intermediate platform chemical. Succinic acid is a further example of a highly promising biobased C4 monomer that has been identified as one of the top twelve sugar-based building blocks by the US Department of Energy. ${ }^{53}$ This renewable bifunctional acid can be prepared from biomass-derived furan compounds through a metal-free oxidative synthesis using a heterogeneous acid catalyst with hydrogen peroxide. ${ }^{53}$

To the best of our knowledge, the investigation of structure-properties relationship of branched polyesters prepared from hemicellulose-derived building blocks, mentioned above, is examined herein for the first time. Apart from these sugarderived diacid, a vegetable oil-derived bifunctional diacid monomer, namely azelaic acid, was also used to shed light on the effect of the chain length of the acid part on the properties of the polyesters. This diacid is extracted from plant source or prepared from oleic acid through its ozonolysis. ${ }^{54,55}$ In this context, the aim of this work was to prepare through melt polycondensation fully biobased branched polyesters, wherein the effect of structural features of the used building blocks, namely aliphatic diacid with triols on the final properties the resulting polymers, were deeply investigated.

\section{Experimental section}

\subsection{Materials}

1,2,6-Hexanetriol (HTO, purum 96\%), 1,2,4-butanetriol (BTO, purum $>90 \%$ ), succinic acid (SucA, purum 99\%), adipic acid (AdiA, purum 99.5\%) and azelaïc acid (AzeA, purum 98\%), reagents, tertrabutyl titanate (TBT) catalyst, were purchased from Sigma-Aldrich. All other solvents and materials used were of analytical grade.

\subsection{Polymer synthesis}

The BiMolecular Non-Linear Polymerization methodology (BMNLP) was used to set the conditions for the synthesis of
BPE by step-growth polymerization approach, in order to adjust their structural features particularly their end groups. ${ }^{56}$ As relevant reported examples, but not limited to, BMNLP strategy has been used to synthesize various hyperbranched polyurethanes, polyesters, polyethers, polyamides, as well as polycarbosiloxanes and polysiloxanes. ${ }^{57-62}$ Developed by Flory and Stockmayer, ${ }^{63,64}$ this method allows the prediction of a number of properties of the branching reaction which can undergo gelation by establishing the criterion for the gelation of the reactive system in terms of molar ratios of the reactive groups. In this method, the critical conditions for gelation to accommodate arbitrary functionalities of the reactive monomers in an $\left[a \mathrm{~A}_{x}+b \mathrm{~B}_{y}\right]$ system where $x \geq 2$ and $y \geq 3$ are generalized in the following equation:

$$
r p_{\mathrm{A}}^{2} \geq 1 /(x-1)(y-1)
$$

with $r$ as the ratio of the number of $\mathrm{A}$ and $\mathrm{B}$ groups initially present in the system and $p_{\mathrm{A}}$ and $p_{\mathrm{B}}$ the probability that that groups A or B respectively have reacted between them at any stage of the reaction.

Hence, if $\mathrm{A}$ is the minor component a soluble branched material is obtained when

$$
r p_{\mathrm{A}}^{2}>(x-1)(y-1)
$$

and if $\mathrm{B}$ is the minor component, it will obtained when ${p_{\mathrm{B}}}^{2} / r<$ $1 /(x-1)(y-1)$.

Thus, for example if all $\mathrm{B}$ groups present in the $a \mathrm{~A}_{x}+b \mathrm{~B}_{y}$ system react, a branched polymer having A end-groups will be formed without gelation if: $r>(x-1)(y-1)$ with $r=a x / b y$.

And if all A groups react, a soluble branched polymer with $B$ end-groups will be formed if

$$
r<1 /(1-x)(1-y) .
$$

Based on this method it is assumedly possible to predict the chain termination of branched polyesters. Thus, polyesters derived from BTO or HTO with AzeA, SucA or AdiA with either hydroxyl or carboxyl end-chain end groups were synthetized and characterized. In the present work, A is corresponding to di-carboxylic acid compounds such as AzeA, SucA or AdiA $(x=2)$ and $\mathrm{B}$ to multifunctional alcohols such as BTO and HTO $(y=3)$. Hence, the reaction system corresponds to $\left[a \mathrm{~A}_{2}+\right.$ $\left.b \mathrm{~B}_{3}\right]$, and therefore it is expected to form a branched polyester material by a step-growth polymerization reaction in equimolar quantities of functional groups.

2.2.1 BPE bearing carboxyl end groups. BPE samples bearing $\mathrm{COOH}$ end-groups were synthesized via the two-stage polycondensation procedure (esterification and polycondensation) in an autoclave reactor equipped with mechanical stirrer. Predetermined amount of SucA, AdiA or AzeA diacid and BTO or HTO aliphatic triol with molar ratio of diacid : triol of $4: 1$ were fed into the reactor with 400 ppm of TBT catalyst. In the first stage, esterification reaction was carried out under a mild nitrogen flow at the temperature range of $160-190{ }^{\circ} \mathrm{C}$. This reaction lasted for $4 \mathrm{~h}\left(1.5 \mathrm{~h}\right.$ at $160^{\circ} \mathrm{C}, 1 \mathrm{~h}$ at $170{ }^{\circ} \mathrm{C}, 1 \mathrm{~h}$ at $180{ }^{\circ} \mathrm{C}$, and for an additional $0.5 \mathrm{~h}$ at $190{ }^{\circ} \mathrm{C}$ ). In the second 
step, the polycondensation was performed under a high vacuum of 100 mbar slowly applied over a time of $20 \mathrm{~min}$ to minimize the oligomers sublimation. The temperature of the mixture was raised to $210-230^{\circ} \mathrm{C}$ stepwise $\left(1.5 \mathrm{~h}\right.$ at $210^{\circ} \mathrm{C}, 1 \mathrm{~h}$ at $220^{\circ} \mathrm{C}$, and for $0.5 \mathrm{~h}$ at $230{ }^{\circ} \mathrm{C}$ ). To purify the resulting BEPs bearing carboxylic acid end groups by removing unreacted monomers, after cooling down the system to room temperature, the produced BPEs were recovered and dissolved in DMSO and then precipitated in large volume of water (10 times the volume of DMSO) and recovered by filtration. This operation is repeated three times to ensure the elimination of all unreacted monomers and finally the recovered polymers were thoroughly washed by water to remove any residual DMSO before being dried to constant weight at $80^{\circ} \mathrm{C}$ under vacuum. The four BPEs derived from AzeA and AdiA showed waxy-like, while the other two SucA-based BPEs were obtained in powder form. The resulting BPE samples are labelled as follow: SucA/BTO (-COOH), SucA/HTO $(-\mathrm{COOH})$, AdiA/BTO (-COOH), AzeA/BTO (-COOH), AdiA/HTO (-COOH), and AzeA/HTO (-COOH).

2.2.2. BPEs bearing hydroxyl end groups. BPE products with free $-\mathrm{OH}$ end-groups were prepared using exactly the same procedure applied for carboxyl end groups-bearing BPEs. The only difference in synthesis protocol is the molar ratio of the introduced reagents, in which the molar feed amounts of diacid/triol used was $1 / 3$. The synthesized PBEs bearing hydroxyl end groups were purified using similar procedure as for BEPs bearing carboxylic end groups. Briefly they were first dissolved in DMSO followed by precipitation in water (using 10 times volume of DMSO) and then filtration. They were then washed by water to remove any residual DMSO and dried to constant weight under vacuum at $80{ }^{\circ} \mathrm{C}$. These BPE samples, obtained as highly viscous liquid, are tagged as follow: SucA/ BTO $(-\mathrm{OH})$, SucA/HTO $(-\mathrm{OH})$, AdiA/BTO $(-\mathrm{OH})$, AzeA/BTO $(-\mathrm{OH}), \operatorname{AdiA} / \mathrm{HTO}(-\mathrm{OH})$, and AzeA/HTO $(-\mathrm{OH})$.

\subsection{Polymer characterization}

2.3.1. Nuclear magnetic resonance (NMR). ${ }^{1} \mathrm{H}$ and ${ }^{13} \mathrm{C}$ NMR spectra were recorded at a frequency of $600 \mathrm{MHz}$ on an AVANCE III HD Bruker spectrometer. Connectivity of the compounds was studied using COSY, HSQC and HMBC 2D NMR spectroscopy. Polyesters were prepared by dissolving the sample in deuterated dimethyl sulfoxide (DMSO- $d_{6}$ ). Proton and carbon NMR chemical shifts are referenced to that of tetramethylsilane (TMS).

2.3.2. Gel permeation chromatography (GPC). GPC was carried out to ascertain the average molecular weights $\left(M_{\mathrm{n}}\right)$ and dispersity (PDI $=M_{\mathrm{w}} / M_{\mathrm{n}}$ ) of all prepared polyesters. A 1260 Infinity II gel permeation chromatograph (GPC, Agilent Technologies, USA) was used, equipped with a refractive index detector at $35{ }^{\circ} \mathrm{C}$, using an Agilent PLgel MIXED-C column. DMF was used as eluent $\left(0.5 \mathrm{ml} \mathrm{min}^{-1}\right)$ at $35^{\circ} \mathrm{C}$ for branched polyesters. Universal calibration was made by using polystyrene standards (Agilent EasiVial PS-M and PSS Polymer Standards), with $M_{\mathrm{p}}$ oscillating from 160 to 1500000.
2.3.3. Differential scanning calorimetry (DSC). Thermal transition behaviour of all prepared polyesters was recorded with a METTLER TOLEDO instrument. Approximately 5-7 mg of sample, sealed in aluminium pan, was heated under nitrogen from -80 to $150{ }^{\circ} \mathrm{C}$ at a heating rate of $10{ }^{\circ} \mathrm{C} \mathrm{min}^{-1}$. The sample was then cooled down to $-80{ }^{\circ} \mathrm{C}$ at $10{ }^{\circ} \mathrm{C} \min ^{-1}$ and held at this temperature for $10 \mathrm{~min}$ to erase any thermal history and heated again for the second heating scan from $-80{ }^{\circ} \mathrm{C}$ to $200{ }^{\circ} \mathrm{C}$ with a heating rate of $10^{\circ} \mathrm{C} \mathrm{min}^{-1}$.

2.3.4. Thermo-gravimetric analysis (TGA). Thermogravimetry analysis measurements were performed using a METTLER TOLEDO instrument. Polyesters samples were heated under nitrogen flow from room temperature to $700{ }^{\circ} \mathrm{C}$ at heating rate of $10^{\circ} \mathrm{C} \min ^{-1}$.

\section{Results and discussion}

\subsection{Synthesis and structural characterization of branched polyesters (BPE)}

The main synthesis routes used to prepare branched polyesters could be divided into two major categories, ${ }^{65}$ that are, singlemonomer methodology (SMM) and double-monomer methodoly (DMM). Polycondensation of $\mathrm{AB}_{n}$ monomers, protontransfer polymerization (PTP), self-condensing ring-opening polymerization (SCROP), and self-condensing vinyl polymerization (SCVP) are some of the specific approaches of the first synthetic technique, SMM. ${ }^{64}$ In contrast, DMM category involves the direct polymerization of two monomers types in order to generate branched polymers. ${ }^{64}$ As presented in Scheme 1, branched polyester samples with either hydroxyl or carboxyl end groups were synthesized in the bulk according to Bimolecular Non-Linear Polymerization (BMNLP) approach. In the esterification stage, predetermined amounts of the diacid (SucA, AdiA or AzeA) and triol (BTO or HTO) were charged in presence of TBT catalyst into an equipped reactor with a mechanical stirrer. The mixture was heated in the $160-190{ }^{\circ} \mathrm{C}$ temperature range and the reaction was proceeded for $4 \mathrm{~h}$ under nitrogen atmosphere. In the second step of synthesis, the polycondensation stage was conducted at $210-230{ }^{\circ} \mathrm{C}$ and was kept proceeding for $3 \mathrm{~h}$ under high vacuum condition of 100 mbar. A molar ratio of diacid/triol of $4 / 1$ or $1 / 3$ was used to prepare BPEs bearing carboxyl and hydroxyl end groups, respectively.

The yields of the branched polyesters materials obtained herein ranged between $80-85 \%$ for those bearing hydroxyl-end groups while the yields were lower (60-67\%) for carboxylended ones owing the lower solubility and loss of materials during the purification step. Both kind of prepared BPEs showed low molecular weights to be in $2730-4860 \mathrm{~g} \mathrm{~mol}^{-1}$ range (Table 1), regardless their terminal units' type $(\mathrm{COOH}$ or $\mathrm{OH})$. These results were speculated owing to the unique macromolecular architectures of the resulting branched networks. High dispersity indices in the 2.8-3.9 range were obtained for both hydroxyl and carboxyl terminated branched polyesters. These high PDI values presented in Table 1 are typical of 
<smiles>[R]C(=O)OC(=O)[18OH]</smiles>

SucA/AdiA/AzeA
ВТО/нTO

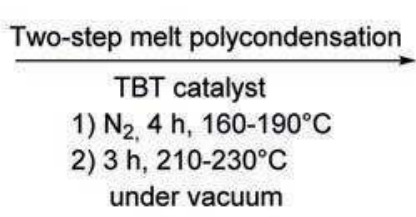<smiles>[R]CCOC(=O)OCC(=O)OCCO</smiles>

12 branched polyesters

$R_{1}=\left\{\begin{array}{l}+\mathrm{CH}_{2} t_{2} \text { SucA } \\ +\mathrm{CH}_{2} t_{4} \text { AdiA } \\ \left.+\mathrm{CH}_{2}\right)_{7} \text { AzeA }\end{array} \quad\right.$ diacid /triol: $x / y=1 / 3 \sim 6$ Hydroxyl end groups-bearing branched polyesters

$\mathrm{R}_{2}=-\mathrm{CH}_{2}-\mathrm{BTO},+\mathrm{CH}_{2} \digamma_{3}$ HTO

Scheme 1 Synthesis route of branched polyester-type oligomers.

Table 1 Molecular weights, dispersity indices, and yields of branched polyesters with carboxyl and hydroxyl end-groups

\begin{tabular}{llll}
\hline Polymers samples & Yield $(\%)$ & $M_{\mathrm{n}}{ }^{a}\left(\mathrm{~g} \mathrm{~mol}^{-1}\right)$ & $\mathrm{PDI}^{b}$ \\
\hline SucA/BTO (-COOH) & 67 & 4250 & 3.1 \\
SucA/HTO (-COOH) & 64 & 4300 & 3.7 \\
AdiA/BTO (-COOH) & 65 & 4720 & 2.8 \\
AdiA/HTO (-COOH) & 60 & 3850 & 3.9 \\
AzeA/BTO (-COOH) & 66 & 4860 & 3.4 \\
AzeA/HTO (-COOH) & 61 & 3350 & 2.9 \\
SucA/BTO (-OH) & 83 & 2980 & 3.9 \\
SucA/HTO (-OH) & 85 & 3540 & 3.7 \\
AdiA/BTO (-OH) & 80 & 3070 & 3.0 \\
AdiA/HTO (-OH) & 80 & 3680 & 2.9 \\
AzeA/BTO (-OH) & 84 & 2730 & 3.4 \\
AzeA/HTO (-OH) & 82 & 3190 &
\end{tabular}

${ }^{a}$ Determined by GPC analysis. ${ }^{b}$ Determined as $M_{\mathrm{w}} / M_{\mathrm{n}}$.

branched structures. ${ }^{66,67}$ It is worth mentioning that these $M_{\mathrm{n}}$ values determined by GPC in DMF give only estimations rather than absolute values giving the lack of standard references for such kind of polymers.

The chemical structure of all carboxyl and hydroxyl-terminated branched polyester samples was characterized by FT-IR spectroscopy, and the results are illustrated in Fig. 1. The obtained data serves as supportive and complementary evidence for the ${ }^{1} \mathrm{H}$ and ${ }^{13} \mathrm{C}$ NMR results (to be discussed later). FTIR spectra of both branched polyesters series either with terminal - $\mathrm{COOH}$ groups or $-\mathrm{OH}$ end groups-bearing polyesters showed two absorption bands at 2940 and $2870 \mathrm{~cm}^{-1}$ assigned to the aliphatic $\mathrm{C}-\mathrm{H}$ symmetric and asymmetric stretching. Another typical band near $1170 \mathrm{~cm}^{-1}$ is due to $\mathrm{C}-\mathrm{O}-\mathrm{C}$ stretching mode of the ester group. The main difference in FTIR spectra of all branched polyesters lies in the fact that the hydroxyl-terminated samples revealed a wide absorption band centered at around $3370 \mathrm{~cm}^{-1}$. The latter is due to the stretching vibration of hydroxyl group (Fig. 1b). In contrast, for carboxyl-terminated BPEs samples, the aforementioned peak at $3370 \mathrm{~cm}^{-1}$ assigned to terminal $(-\mathrm{OH})$ has disappeared and replaced by a broadened detectable band between 3100 and
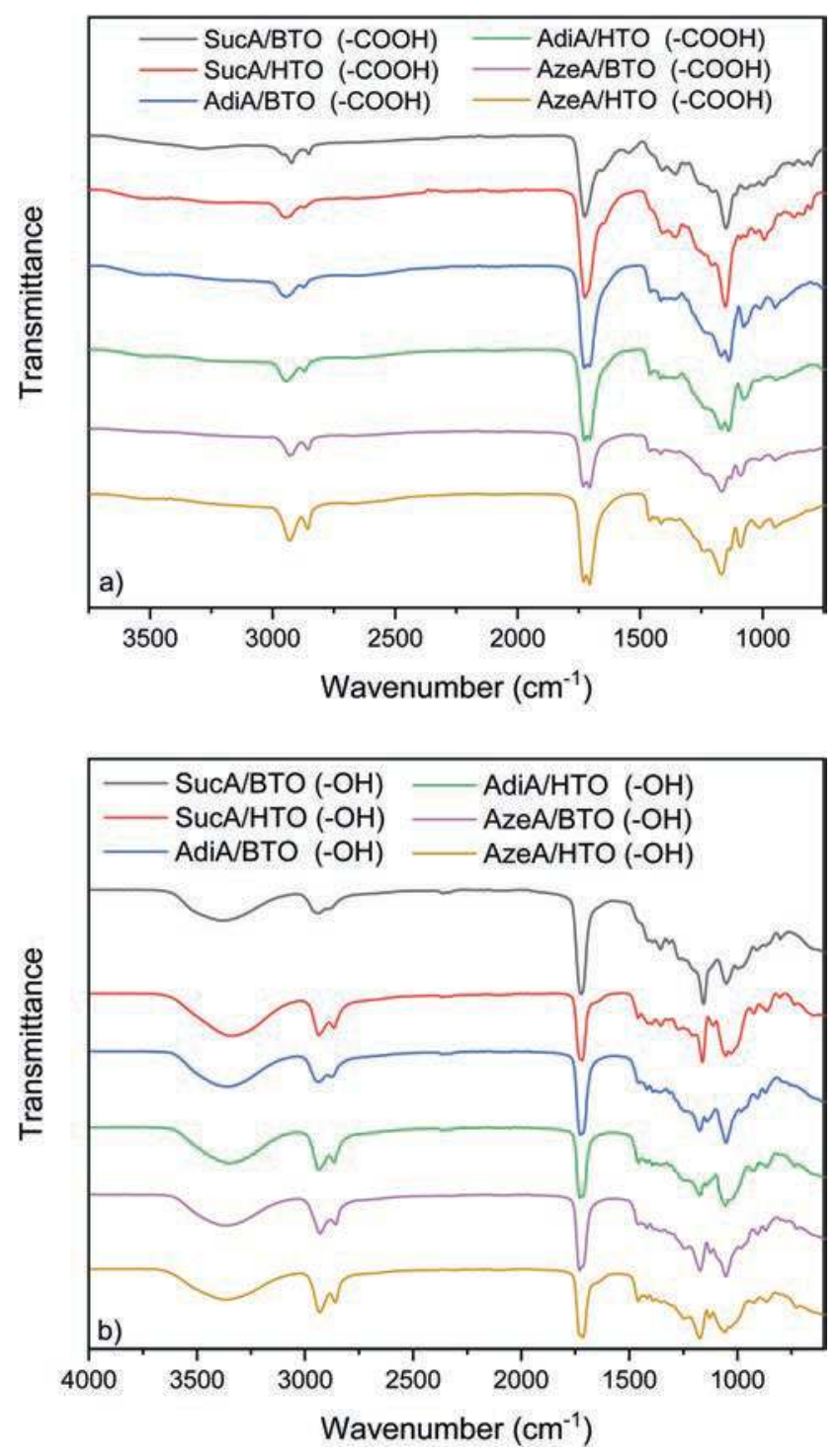

Fig. 1 FT-IR spectra of branched polyesters bearing: (a) terminal carboxyl, and (b) terminal hydroxyl groups. 
$3350 \mathrm{~cm}^{-1}$, originating from the free carboxyl functional groups (Fig. 1a). Comparison with the carboxyl-terminated branched polyesters illustrates that the characteristic absorption bands originated from ester carbonyl stretching $(v \mathrm{C}=\mathrm{O})$ in hydroxyl-terminated BPEs were shifted to higher wavenumbers (from 1720 to $1727 \mathrm{~cm}^{-1}$ ). This is understandable owing to the formation of strong hydrogen-bonding interactions between the carbonyl of the ester moiety and the free terminal $-\mathrm{COOH}$ groups in carboxyl-terminated BPEs networks. ${ }^{68}$ This hence leads to a pronounced downshift of $13-18 \mathrm{~cm}^{-1}$ in $(v \mathrm{C}=\mathrm{O})$ stretching frequency. Importantly, for all $\mathrm{COOH}$-terminated BPEs, in addition to the characteristic ester carbonyl band at $1720 \mathrm{~cm}^{-1}$, an additional band typical of the free carboxylic acid carbonyl appeared at around $1733 \mathrm{~cm}^{-1}$. The presence of the latter, which overlapped with the main ester bond $(v \mathrm{C}=\mathrm{O})$, prominently proves the successful synthesis of BPEs materials with carboxyl end groups. Similar finding was described in literature. ${ }^{69}$

In order to gain better insight into their fine chemical structure, all the novel branched polyesters developed in the present work were studied by 1D and 2D NMR spectroscopy. The individual spin systems of the alcohols and acids could be identified using COSY and multiplicity edited HSQC allows to differentiate the alcohols' $\mathrm{CH}, \mathrm{CH}_{2}$ and free $\mathrm{OH}$ groups. The connectivity between the carbon atoms and in particular between the acid and ester carbonyl groups was ascertained using HMBC. All the $1 \mathrm{D}$ and $2 \mathrm{D}$ spectra are given in the SI (Fig. S1-S60 ${ }^{\circ}$ ). The ${ }^{1} \mathrm{H}$ and ${ }^{13} \mathrm{C}$ NMR chemical shifts of attributed to all protons and carbons in the acid and hydroxyl-ended branched polyesters samples are reported in Tables S1-4. $\dagger$

In order to explain the assignment process, the spectrum of AdiA/BTO $(-\mathrm{COOH})$ was considered as example. Both the ${ }^{1} \mathrm{H}$
(Fig. 2 top) and ${ }^{13} \mathrm{C}$ (Fig. 2 left) feature multiple signals for most atoms due to the multiple isomeric forms present. There are several signals in the carbonyl region, at 174.7 , as well as beween 173.2 and $172.5 \mathrm{ppm}$, the most deshielded of which corresponds to the acid function, while the others are esters. This is confirmed by the cross peaks between triol resonances and the high-field signal in the HMBC (Fig. 2, green). On this basis both $\alpha$ and $\alpha^{\prime}$ resonances can be assigned to the signals at 2.3 and $2.2 \mathrm{ppm}$, respectively. The absence of remaining unreacted diacid can be warranted on the basis of the integrals for these two latter signals. The signals for at least the major forms could be identified on the basis of the HSQC (Fig. 2, red and blue), HMBC (Fig. 2, green) and COSY (Fig. S13†) crosspeaks.

In the case of hydroxyl-ended polyesters, AzeA/HTO $(-\mathrm{OH})$ was taken as example for peaks assignments. The multiplicity edited HSQC spectrum (Fig. 3) features 2 groups of both methine and methylene signals. The HMBC spectrum (Fig. S60 $\dagger$ ) shows that the methine signals in the range 4.7-5.0 $\mathrm{ppm}{ }^{1} \mathrm{H} / 70-76 \mathrm{ppm}{ }^{13} \mathrm{C}$ and the methylene signals in the range between $3.8-4.2 \mathrm{ppm}{ }^{1} \mathrm{H} / 63-70 \mathrm{ppm}{ }^{13} \mathrm{C}$ correlate with ${ }^{13} \mathrm{C}$ ester signals around $173 \mathrm{ppm}$, therewith establishing that these methine and methylene signals correspond to esterified species. On the other hand, the methine signals in the range between 3.3-3.7 $\mathrm{ppm}{ }^{1} \mathrm{H} / 65-73 \mathrm{ppm}{ }^{13} \mathrm{C}$ and the methylene signals in the range between $3.2-3.5 \mathrm{ppm}{ }^{1} \mathrm{H} / 60-68 \mathrm{ppm}$ ${ }^{13} \mathrm{C}$ do not show any such correlations and therefore correspond to non-esterified groups. This fact is corroborated by the COSY cross-peaks these latter resonances show with the hydroxyl signals at 4.3-4.5 ppm (see Fig. S58†). The hydroxy

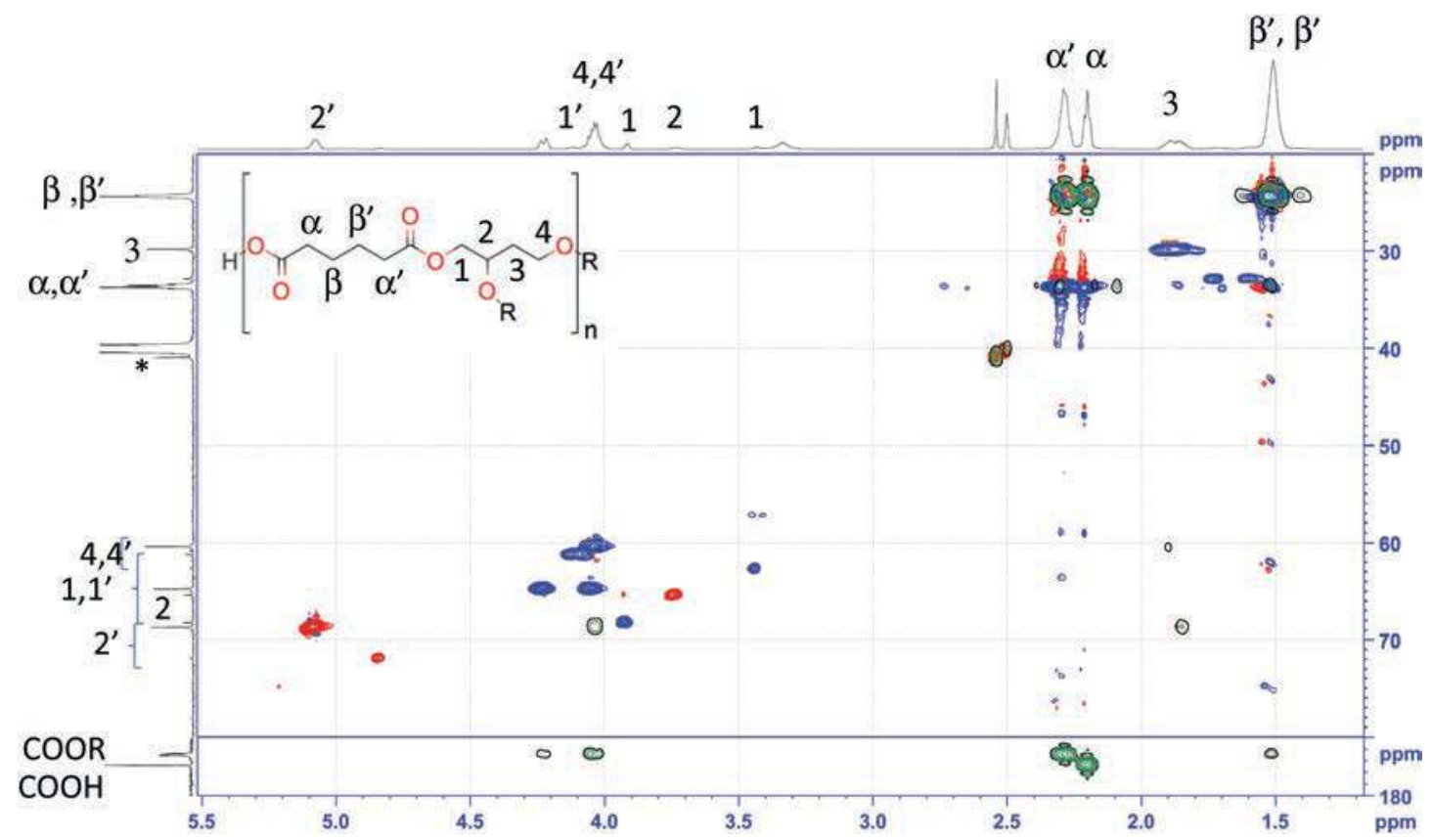

Fig. 2 Superposition of HSQC (red and blue) and HMBC (green) spectra of AdiA/BTO(-COOH) (recorded in DMSO- $d_{6}$ ) and assignments to ${ }^{1} \mathrm{H}$ (top trace) and ${ }^{13} \mathrm{C}$ (bottom trace) $(\mathrm{R}=\mathrm{H}$ or AdiA). 


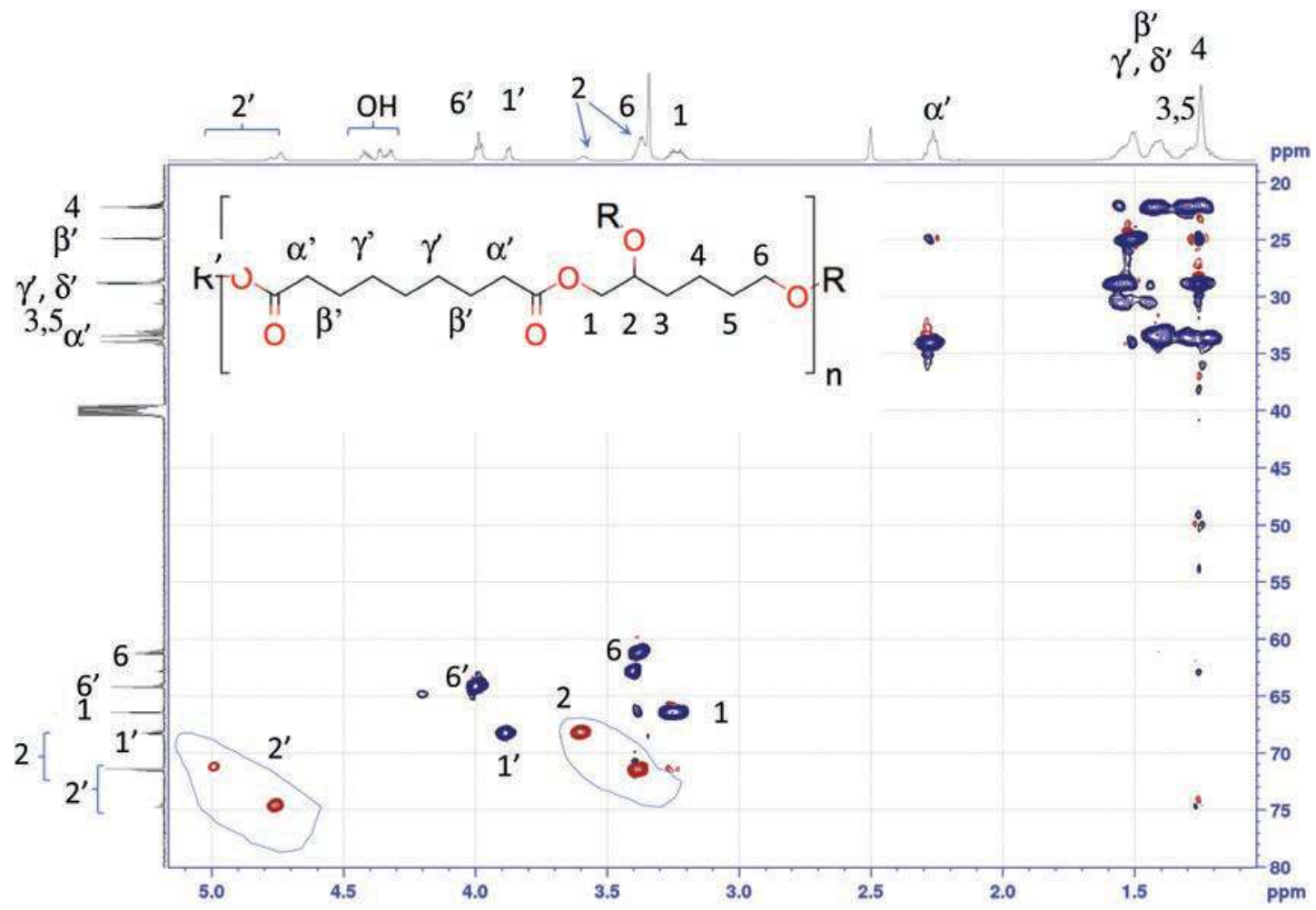

Fig. $3 \mathrm{HSQC}$ NMR spectra of AzeA/HTO(-OH) (recorded in DMSO- $d_{6}$ ) and assignments to ${ }^{1} \mathrm{H}$ (top trace) and ${ }^{13} \mathrm{C}$ (left trace) spectra $(\mathrm{R}=\mathrm{H}$ or AzeA, $\mathrm{R}^{\prime}=\mathrm{H}$ or $\left.\mathrm{HTO}\right)$.

signals are clearly identified as such by the absence of any cross-peak at these positions in the HSQC spectrum (Fig. 3).

The estimation of the $-\mathrm{COOH}$ end groups was performed by the integration of their respective peaks in the NMR spectra. The results showed that AdiA/BTO and AdiA/HTO have respectively a molar fraction of 0.56 and 0.68 of $-\mathrm{COOH}$ end groups of the total diacid units. AzeA based BPEs showed a higher amount of $-\mathrm{COOH}$ end groups as the molar fraction of $\mathrm{COOH}$ end groups was around 0.9 for both AzeA/BTO and AzeA/HTO. However, in the case of SucA-based BPEs, the estimation of $\mathrm{COOH}$ end groups was not possible because of the strong overlapping signals between those corresponding to esterified units and free end groups of this diacid.

Similarly, to COOH-terminated BEPs the estimation of the -OH end groups in hydroxyl terminated BEPs was also performed by the integration of the peaks of $\mathrm{OH}$ end groups in the NMR spectra. The results showed that the molar fraction of $\mathrm{OH}$ terminal groups ranged from 0.42 to 0.65 . Indeed, the values of the molar fraction were as following: 0.57 for SucA/ BTO, 0.62 for SucA/HTO, 0.65 AdiA/BTO, 0.42 for AdiA/HTO, 0.62 for AzeA/BTO and 0.56 for AzeA/HTO.

\subsection{Thermal properties of polyesters}

The thermal properties of the produced branched polyesters were analysed by DSC and TGA to thoroughly investigate the thermal properties and stability. The DSC analyses of the puri- fied BPE samples with - $\mathrm{COOH}$ end groups showed that neither crystallization nor melting endotherms can be detected during the heating scans, hence confirming as expected the wholly amorphous nature of the resulting materials. The recorded data related to glass transition are collected in Table 2. It is worth noting that regardless of the used diacid type, BTObased polyesters possess slightly higher glass transition temperatures than their counterpart derived from HTO, wherein $T_{\mathrm{g}}$ values of 19.7 vs. $18.5,-23{ }^{\circ} \mathrm{C}$ vs. $-28.3{ }^{\circ} \mathrm{C}$, and -37.1 vs. $-37.7^{\circ} \mathrm{C}$ were found for the samples derived from SucA, AdiA, and AzeA diacid, respectively. As expected, DSC results revealed an obvious correspondence between the $T_{\mathrm{g}}$ value and the chain length of the diacids incorporated into the synthesized polyesters. For BTO-based BPE with terminal carboxyl groups, $T_{\mathrm{g}}$ of polymers was dramatically shifted to a much higher temperature from $-37.1{ }^{\circ} \mathrm{C}$ to $-23^{\circ} \mathrm{C}$, and then to $19.7^{\circ} \mathrm{C}$ with replacing AzeA with AdiA and SucA diacid, respectively. In fact, we also noticed that the $T_{\mathrm{g}}$ of the polyesters derived from HTO showed a very similar trend of those for BTO-based ones, where polymer containing shorter-chain dicarboxylic acid (AdiA or SucA) exhibited much higher $T_{\mathrm{g}}$ than that of the counterpart prepared from longer-chain diacid (AzeA). In other words, these findings reported herein mainly arise from the replacement of a highly flexible diacid moiety by a more rigid diacid structure which, by reducing chain mobility, results in a remarkable increase in $T_{\mathrm{g}}$. To sum up, interestingly to highlight that the effect of the diacid type with different chain 
Table 2 Thermal properties of prepared branched polyesters bearing carboxyl and hydroxyl end-groups

\begin{tabular}{lllll}
\hline Samples & $T_{\mathrm{d}, 5 \%}$ & $T_{\mathrm{d}, 10 \%}$ & $R_{500{ }^{\circ} \mathrm{C}}(\%)$ & $T_{\mathrm{g}}^{*}\left({ }^{\circ} \mathrm{C}\right)$ \\
\hline SucA/BTO (-COOH) & 216.8 & 249 & 6.9 & 19.7 \\
SucA/HTO (-COOH) & 227.3 & 252.2 & 6.0 & 18.5 \\
AdiA/BTO (-COOH) & 180.5 & 264.6 & 5.3 & -23.0 \\
AdiA/HTO (-COOH) & 268.3 & 303 & 3.4 & -28.3 \\
AzeA/BTO (-COOH) & 203.6 & 249.5 & 2.9 & -37.1 \\
AzeA/HTO (-COOH) & 229.1 & 260.3 & 1.8 & -37.7 \\
SucA/BTO (-OH) & 187.8 & 226.5 & 4.1 & -18.9 \\
SucA/HTO (-OH) & 213.5 & 229.7 & 1.0 & -53.2 \\
AdiA/BTO (-OH) & 168.3 & 203.0 & 4.3 & -52.1 \\
AdiA/HTO (-OH) & 226.3 & 257.5 & 3.0 & -56.7 \\
AzeA/BTO (-OH) & 193.1 & 221.0 & 2.5 & -57.2 \\
AzeA/HTO (-OH) & 236.7 & 257.7 & 1.7 & -57.9
\end{tabular}

length on $T_{\mathrm{g}}$ increase was much more pronounced than that of triol type used. As it can be seen from DSC trace of AzeA/HTO $(-\mathrm{COOH})$ branched polyester, an endothermic peak at temperature above the $T_{\mathrm{g}}\left(-21.4^{\circ} \mathrm{C}\right)$ was clearly spotted. This behaviour may be ascribed to the physical aging phenomenon by enthalpy relaxation owing to a non-equilibrium state (instability) of the amorphous material in the glassy state. ${ }^{70}$ For the sake of comparison with their linear polyesters analogues, the three carboxyl-terminated branched polyesters made from BTO showed significantly higher $T_{\mathrm{g}}$ values than their linear analogues prepared from the same diacids but using 1,4-butanediol (BDO). ${ }^{71,72}$ Indeed, the linear polyesters combining SucA/ BDO, AdiA/BDO and AzeA/BDO exhibited $T_{\mathrm{g}}$ values of $-36{ }^{\circ} \mathrm{C}$, $-76{ }^{\circ} \mathrm{C}$ and $-62{ }^{\circ} \mathrm{C}$, respectively (vs. $19.7{ }^{\circ} \mathrm{C},-23{ }^{\circ} \mathrm{C}$, and $-37.1{ }^{\circ} \mathrm{C}$ for $\mathrm{BTO}$-based BPEs, respectively). Moreover, the linear polyesters were semicrystalline contrarily to the branched ones prepared herein that were amorphous. Similarly, branched carboxylic-terminated polyesters based on HTO in combination with SucA or AdiA showed much higher values with respect to their linear counterparts derived from 1,6-hexanediol (HDO). ${ }^{73,74}$ The $T_{\mathrm{g}}$ of the linear SucA/HDO and AdiA/HDO based polyesters were $-40{ }^{\circ} \mathrm{C}$ and $-28.3^{\circ} \mathrm{C}$ respectively against $18.5^{\circ} \mathrm{C}$ and $-28.3^{\circ} \mathrm{C}$ for BPEs based on SucA/ HTO and AdiA/HTO respectively.

The thermal degradation behaviour and stability of the resulting carboxyl-terminal BPEs were assessed by TGA analysis under nitrogen atmosphere. The typical profiles are shown in Fig. 4 and the 5\%, 10\% decomposition temperatures as well as the residue at $500{ }^{\circ} \mathrm{C}$ are given in Table 2 . It was found that all the prepared fully biobased polyesters, except AdiA/HTO (-COOH), revealed high thermal stability over $200{ }^{\circ} \mathrm{C}$ with onset decomposition temperatures $\left(T_{\mathrm{d}, 5 \%}\right)$ oscillating from 180.5 to $268.3{ }^{\circ} \mathrm{C}$, leaving just $1.8-6.9 \%$ of residual weight upon heating to $500{ }^{\circ} \mathrm{C}$. Only a single stage thermal degradation was observed for the two AdiA-based polymers, while the other four polyesters samples degraded by multistage process. It was found that polyester derived from HTO was much more thermally stable than the BTO-based sample. Indeed, polymers prepared from HTO showed a much higher $T_{\mathrm{d}, 5 \%}$ value of 221.7 vs. $216.8{ }^{\circ} \mathrm{C}$ (for BTO-based sample), 268.3

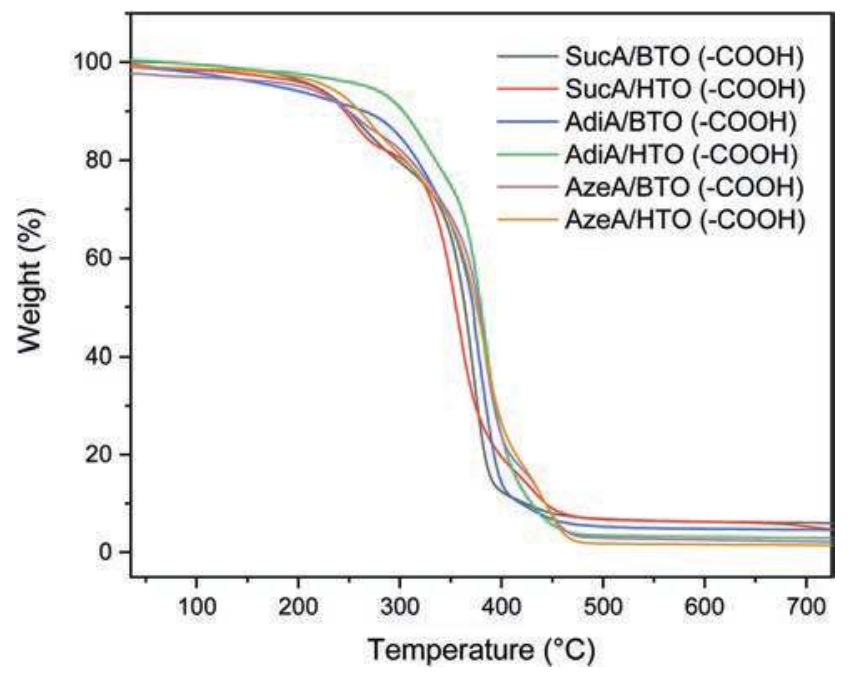

Fig. 4 TGA thermograms of carboxyl-terminated branched polyesters.

vs. $180.5{ }^{\circ} \mathrm{C}, 229.1$ vs. $203.6{ }^{\circ} \mathrm{C}$, respectively for SucA, AdiA, and AzeA-based polyesters. This finding is in good agreement with the reported TGA results in Barrett study, ${ }^{75}$ where polyesters derived from HTO showed a much higher stability compared with BTO-based samples. It seems that the presence of a long-chain hexamethylene unit (HTO) into the branched polyester backbone having - $\mathrm{COOH}$ functional end groups play the main role in the important delay of the onset of degradation. As shown above in Table 2, the HTO-based polyester prepared from AdiA diacid exhibited much higher heat resistance than its homologue obtained with shorter chain SucA diacid. Hence, a notable difference in $T_{\mathrm{d}, 5 \%}$ values of $41{ }^{\circ} \mathrm{C}$ was obtained for these two samples using HTO. It is worthy to note that BTO-based polymers present a similar trend as HTObased samples, where polyester having the longest aliphatic diacid (AzeA) revealed higher thermal stability than other polyesters with shorter spacer length of diacid, AdiA ( $T_{\mathrm{d}, 5 \%}$ values of 203.6 vs. $180.5{ }^{\circ} \mathrm{C}$ for AzeA/BTO $(-\mathrm{COOH})$, and AdiA/BTO $(-\mathrm{COOH})$, respectively). This is most likely due to the presence of a long-chain aliphatic diacid incorporated into the polyesters' macromolecular chain, which obviously improved their thermal stability by delaying the onset of degradation $T_{\mathrm{d}, 5 \%}$. This outcome is consistent with a previous study reporting that the longer straight aliphatic diacid chain is, the more vulnerable to thermal degradation is. ${ }^{76}$ To sum up, the above results highlighted that the superior thermal stability of the six carboxyl-terminated BPEs, derived from fully renewable resources, ensures their safe thermal processing at temperature much higher than their glass transition temperatures. This characteristic makes them suitable candidates (as polymer blend component or as co-units in copolyesters) for heat processing applications such injection molding.

The six synthesized branched polyesters bearing hydroxyl end groups were also analyzed by DSC to examine the effects of the flexible chains length of used both diacids and triols on their thermal behaviour characteristics. Table 2 gathers the recorded glass transition temperatures for the produced poly- 
esters. It can be concluded from the latter that as expected all resulting hydroxyl end groups-bearing BPEs polymers did not show any crystallization or melting peaks demonstrating their amorphous nature. The new fully renewable materials exhibited a very wide glass transition temperature $\left(T_{\mathrm{g}}\right)$ range oscillating from -57.9 to $-18.9^{\circ} \mathrm{C}$. As expected from the structure of BTO and HTO having different length alkane chains, we found that for the same diacid, $T_{\mathrm{g}}$ values of polymers samples derived from BTO are higher than those of the polyesters made from HTO (exhibiting values of -18.9 vs. $-53.2^{\circ} \mathrm{C},-52.1$ vs. $-56.7^{\circ} \mathrm{C}$, and -57.2 vs. $-57.9^{\circ} \mathrm{C}$ for SucA, AdiA, and AzeAbased materials, respectively). Such outcome can be mainly ascribed to the rigidity of the obtained polyester, where one aliphatic triol moiety (HTO) is substituted by a stiffer triol moiety (BTO). This endows less mobility to the chain, resulting thereby to higher $T_{\mathrm{g}}$ value. Comparing the thermal properties results of the sustainable BPEs with $-\mathrm{OH}$ and $-\mathrm{COOH}$ end groups, a great difference could be readily spotted independently from the used biobased triol (BTO or HTO). Interestingly, much higher $T_{\mathrm{g}}$ were recorded for all synthesized BPEs with terminal carboxyl groups compared to those of the same samples bearing -OH end groups. SucA-based polyesters have been used as relevant example for illustrative purposes. Indeed, the $T_{\mathrm{g}}$ value of SucA/HTO sample dramatically increased from -53.2 to $18.5{ }^{\circ} \mathrm{C}$ with changing the end groups type from $-\mathrm{OH}$ to $-\mathrm{COOH}$ ones, respectively. We noticed that SucA/BTO polyesters showed also the same discernible trend as that in SucA/HTO sample, but the hydroxyl groups-terminated polymer revealed a much lower $T_{\mathrm{g}}$ value compared to the same branched polyester having carboxyl functions as terminal units (-18.9 vs. $\left.19.7^{\circ} \mathrm{C}\right)$. As seen from DSC data, the other AdiA and AzeA-based polyesters also show the same tendency. Once the hydroxyl end groups were replaced by carboxyl terminal ones into the same polymer sample, a remarkable increment of their $T_{\mathrm{g}}$ is observed regardless the involved triol (BTO or HTO). In fact, a huge difference in the $T_{\mathrm{g}}$ at least by $20{ }^{\circ} \mathrm{C}$ was detected between BPE samples terminated with $\mathrm{OH}$ and $\mathrm{COOH}$ functional end groups. This significant $T_{\mathrm{g}}$ increase in carboxyl-terminated polymers could be explained by the formation of hydrogen bonding between the free carboxyl end groups of polyesters. This promotes much greater intermolecular cohesion than dipole-dipole interaction, thereby obtaining higher $T_{\mathrm{g}}$ values in branched polyesters bearing $-\mathrm{COOH}$ end groups. This finding is in good agreement with what was reported in a previous work in literature. ${ }^{77}$ To recapitulate, the aforementioned upshots proved that the $T_{\mathrm{g}}$ of all twelve prepared branched polyesters strongly depends on the nature of the end-groups $(-\mathrm{OH}$ or $-\mathrm{COOH})$.

Thermal stability of the novel branched polyesters samples bearing hydroxyl end groups were investigated by thermogravimetric analysis as depicted in Fig. 5. All prepared polymers exhibit a classical two-step weight loss. The pertinent decomposition parameters including the degradation temperatures at $5 \%$ and $10 \%$ weight loss as well as the residue at $500{ }^{\circ} \mathrm{C}$ are listed in Table 2 . A significant difference in thermal stability was observed among them across the whole tempera-

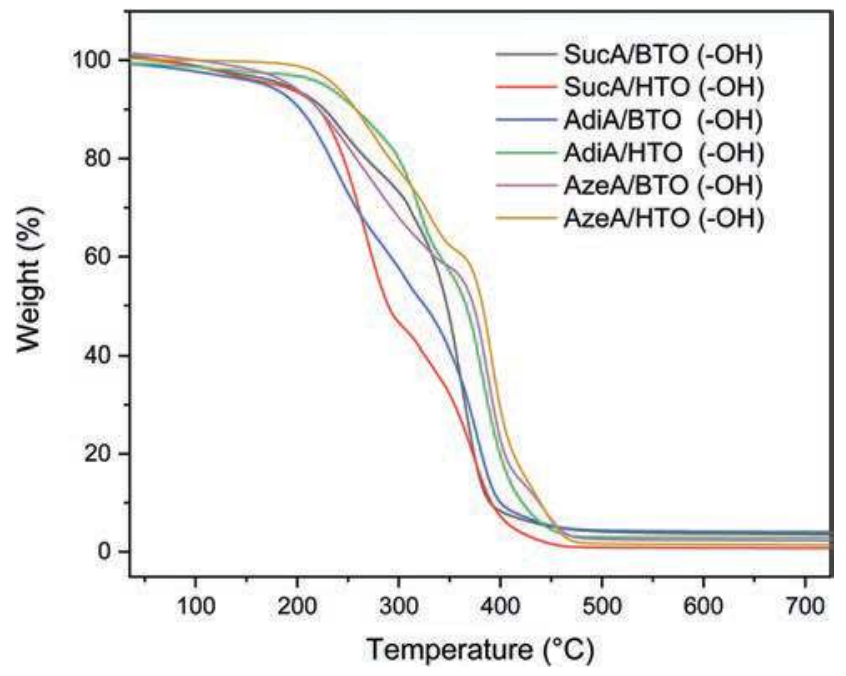

Fig. 5 TGA thermograms of hydroxyl-terminated branched polyesters.

ture range. Like branched polymers bearing carboxyl endgroups, it was found that hydroxyl-terminated polyesters derived from HTO were also much more thermally stable than the BTO-based samples. These HTO-based polymers, characterized by good resistance to heat, exhibited onset degradation temperature $\left(T_{\mathrm{d}, 5 \%}\right)$ values ranging between 213.5 and $236.7^{\circ} \mathrm{C}$ (vs. much lower $T_{\mathrm{d}, 5 \%}$ values appearing in the $168.3-193.1{ }^{\circ} \mathrm{C}$ range for the BTO-based samples). In more detail, a difference in $T_{\mathrm{d}, 5 \%}$ of about $25^{\circ} \mathrm{C}, 58^{\circ} \mathrm{C}$, and $43^{\circ} \mathrm{C}$ is obtained between HTO and BTO-based polymer for SucA, AdiA, and AzeA-based polyesters, respectively. The six renewable resources-based materials developed displayed low residual weight percentage at $500{ }^{\circ} \mathrm{C}$, leaving a $1 \%$ and $4.3 \%$ of degradation residues. To recapitulate, it is worthy to highlight that one of the most outstanding features of these new branched polyesters bearing $\mathrm{OH}$ end groups is their very wide temperature window of processing up to $294{ }^{\circ} \mathrm{C}$ above their $T_{\mathrm{g}}$. This feature opens the door for their exploitation as new class of thermally stable biobased materials with unique macromolecular architectures in a wide range of potential applications such as injection molding and extrusion.

\section{Conclusion}

In this study, biobased aliphatic polyols bearing three hydroxyl groups (triols) as well as dicarboxylic acids that can be derived from renewable feedstock particularly hemicellulosic sugars were used to prepare branched polyesters through melt polycondensation method. A systematic combination of various building blocks having different structures allowed the synthesis of polymers with different structural features enabling, for the first time to our knowledge, the establishment of the structure/property relationship for such fully biobased polyesters. The understanding of these links particularly in term of thermal properties that are fundamental to determine their 
processability and application domains was established. The study reveals furthermore the importance of the use of sugarderived intermediate as promising precursors for the synthesis of high-performance eco-friendly materials in various structure. This methodical study can be used as the basis for the selection of suitable building blocks and their combination to access fully biobased branched polyester with giving properties for targeted applications. Undoubtedly the potential of the synthesized final materials for various uses is undeniable but the extension to other similar building blocks as well as the various combination through co-polymerization, chain extension and/or crosslinking, etc. can be pursued paving thus the way to wide range of functional polyesters with broad application domains.

\section{Conflicts of interest}

There are no conflicts to declare.

\section{Acknowledgements}

The authors are grateful to the Luxembourg National Research Fond (FNR) for financial support (CATBIOSE project INTER/ ANR 15/9903334). We would like to acknowledge Coraline Sirot, Régis Vaudemont and Benoît Marcolini who continuously provide a friendly and supportive environment to help us conduct our work.

\section{References}

1 A. Gandini, Polymers from Renewable Resources: A Challenge for the Future of Macromolecular Materials, Macromolecules, 2008, 41(24), 9491-9504.

2 A. Gandini, The irruption of polymers from renewable resources on the scene of macromolecular science and technology, Green Chem., 2011, 13(5), 1061-1083.

3 T. Iwata, Biodegradable and Bio-Based Polymers: Future Prospects of Eco-Friendly Plastics, Angew. Chem., Int. Ed., 2015, 54(11), 3210-3215.

4 M. A. R. Meier, J. O. Metzger and U. S. Schubert, Plant oil renewable resources as green alternatives in polymer science, Chem. Soc. Rev., 2007, 36(11), 1788-1802.

5 C. Vilela, A. F. Sousa, A. C. Fonseca, A. C. Serra, J. F. J. Coelho, C. S. R. Freire and A. J. D. Silvestre, The quest for sustainable polyesters - insights into the future, Polym. Chem., 2014, 5(9), 3119-3141.

6 V. Guillard, S. Gaucel, C. Fornaciari, H. Angellier-Coussy, P. Buche and N. Gontard, The Next Generation of Sustainable Food Packaging to Preserve Our Environment in a Circular Economy Context, Front. Nutr., 2018, 5(121), $1-13$.

7 S. Lambert and M. Wagner, Environmental performance of bio-based and biodegradable plastics: the road ahead, Chem. Soc. Rev., 2017, 46(22), 6855-6871.
8 F. Luzi, L. Torre, J. M. Kenny and D. Puglia, Bio- and FossilBased Polymeric Blends and Nanocomposites for Packaging: Structure-Property Relationship, Materials, 2019, 12(3), 471.

9 European bioplastics. Institute for Bioplastics and Biocomposites, https://www.european-bioplastics.org.

10 Z. Wang, B. Kastern, K. Randazzo, A. Ugrinov, J. Butz, D. W. Seals, M. P. Sibi and Q. R. Chu, Linear polyester synthesized from furfural-based monomer by photoreaction in sunlight, Green Chem., 2015, $17(10)$, 4720-4724.

11 C. Lavilla, A. Alla, A. Martínez de Ilarduya and S. MuñozGuerra, High $\mathrm{Tg}$ Bio-Based Aliphatic Polyesters from Bicyclic d-Mannitol, Biomacromolecules, 2013, 14(3), 781793.

12 P. A. Klonos, L. Papadopoulos, G. Z. Papageorgiou, A. Kyritsis, P. Pissis and D. N. Bikiaris, Interfacial Interactions, Crystallization, and Molecular Dynamics of Renewable Poly (Propylene Furanoate) In Situ Filled with Initial and Surface Functionalized Carbon Nanotubes and Graphene Oxide, J. Phys. Chem. C, 2020, 124(18), 10220-10234.

$13 \mathrm{H}$. Hu, R. Zhang, W. B. Ying, Z. Kong, K. Wang, J. Wang and J. Zhu, Biodegradable Elastomer from 2,5Furandicarboxylic Acid and $\varepsilon$-Caprolactone: Effect of Crystallization on Elasticity, ACS Sustainable Chem. Eng., 2019, 7(21), 17778-17788.

14 J. C. Morales-Huerta, A. Martínez de Ilarduya, S. León and S. Muñoz-Guerra, Isomannide-Containing Poly(butylene 2,5-furandicarboxylate) Copolyesters via Ring Opening Polymerization, Macromolecules, 2018, 51(9), 3340-3350.

15 D. G. Papageorgiou, N. Guigo, V. Tsanaktsis, S. Exarhopoulos, D. N. Bikiaris, N. Sbirrazzuoli and G. Z. Papageorgiou, Fast Crystallization and Melting Behavior of a Long-Spaced Aliphatic Furandicarboxylate Biobased Polyester, Poly(dodecylene 2,5-furanoate), Ind. Eng. Chem. Res., 2016, 55(18), 5315-5326.

16 G. Z. Papageorgiou, D. G. Papageorgiou, Z. Terzopoulou and D. N. Bikiaris, Production of bio-based 2,5-furan dicarboxylate polyesters: Recent progress and critical aspects in their synthesis and thermal properties, Eur. Polym. J., 2016, 83, 202-229.

17 G. Z. Papageorgiou, V. Tsanaktsis, D. G. Papageorgiou, K. Chrissafis, S. Exarhopoulos and D. N. Bikiaris, Furanbased polyesters from renewable resources: Crystallization and thermal degradation behavior of poly(hexamethylene 2,5-furan-dicarboxylate), Eur. Polym. J., 2015, 67, 383-396.

18 M. J. Soares, P.-K. Dannecker, C. Vilela, J. Bastos, M. A. R. Meier and A. F. Sousa, Poly(1,20-eicosanediyl 2,5furandicarboxylate), a biodegradable polyester from renewable resources, Eur. Polym. J., 2017, 90, 301-311.

19 N. Poulopoulou, A. Pipertzis, N. Kasmi, D. N. Bikiaris, D. G. Papageorgiou, G. Floudas and G. Z. Papageorgiou, Green polymeric materials: On the dynamic homogeneity and miscibility of furan-based polyester blends, Polymer, 2019, 174, 187-199.

20 Z. Terzopoulou, L. Papadopoulos, A. Zamboulis, D. G. Papageorgiou, G. Z. Papageorgiou and D. N. Bikiaris, 
Tuning the Properties of Furandicarboxylic Acid-Based Polyesters with Copolymerization: A Review, Polymers, 2020, 12(6), 1209.

21 Z. Terzopoulou, V. Tsanaktsis, D. N. Bikiaris, S. Exarhopoulos, D. G. Papageorgiou and G. Z. Papageorgiou, Biobased poly(ethylene furanoate-coethylene succinate) copolyesters: solid state structure, melting point depression and biodegradability, RSC Adv., 2016, 6(87), 84003-84015.

22 D. N. Bikiaris, G. Z. Papageorgiou and D. S. Achilias, Synthesis and comparative biodegradability studies of three poly(alkylene succinate)s, Polym. Degrad. Stab., 2006, 91(1), 31-43.

23 N. Bosq, N. Guigo, D. Aht-Ong and N. Sbirrazzuoli, Crystallization of Poly(butylene succinate) on Rapid Cooling and Heating: Toward Enhanced Nucleation by Graphene Nanosheets, J. Phys. Chem. C, 2017, 121(21), 11915-11925.

24 M. Gigli, M. Fabbri, N. Lotti, R. Gamberini, B. Rimini and A. Munari, Poly(butylene succinate)-based polyesters for biomedical applications: A review, Eur. Polym. J., 2016, 75, 431-460.

25 D. N. Bikiaris, G. Z. Papageorgiou, S. A. Papadimitriou, E. Karavas and K. Avgoustakis, Novel biodegradable polyester poly(propylene succinate): synthesis and application in the preparation of solid dispersions and nanoparticles of a water-soluble drug, AAPS PharmSciTech, 2009, 10(1), 138-146.

26 J. C. Morales-Huerta, A. Martínez de Ilarduya and S. Muñoz-Guerra, Modulating the Tg of Poly(alkylene succinate)s by Inserting Bio-Based Aromatic Units via RingOpening Copolymerization, Polymers, 2017, 9(12), 701.

27 G. Z. Papageorgiou and D. N. Bikiaris, Biodegradable poly (alkylene succinate) blends: Thermal behavior and miscibility study, J. Polym. Sci., Part B: Polym. Phys., 2006, 44(3), 584-597.

28 G. Z. Papageorgiou and D. N. Bikiaris, Synthesis, Cocrystallization, and Enzymatic Degradation of Novel Poly (butylene-co-propylene succinate) Copolymers, Biomacromolecules, 2007, 8(8), 2437-2449.

29 Z. Li, J. Yang and X. J. Loh, Polyhydroxyalkanoates: opening doors for a sustainable future, NPG Asia Mater., 2016, 8, e265.

$30 \mathrm{~J}$. Xu and B.-H. Guo, Poly(butylene succinate) and its copolymers: Research, development and industrialization, Biotechnol. J., 2010, 5(11), 1149-1163.

31 T. Yokohara, K. Okamoto and M. Yamaguchi, Effect of the shape of dispersed particles on the thermal and mechanical properties of biomass polymer blends composed of poly(L-lactide) and poly(butylene succinate), J. Appl. Polym. Sci., 2010, 117(4), 2226-2232.

32 K. K. Jena, K. V. S. N. Raju, B. Prathab and T. M. Aminabhavi, Hyperbranched Polyesters: Synthesis, Characterization, and Molecular Simulations, J. Phys. Chem. B, 2007, 111(30), 8801-8811.

33 L. Y. Qiu and Y. H. Bae, Polymer Architecture and Drug Delivery, Pharm. Res., 2006, 23(1), 1-30.

34 H. Zhang, A. Patel, A. K. Gaharwar, S. M. Mihaila, G. Iviglia, S. Mukundan, H. Bae, H. Yang and
A. Khademhosseini, Hyperbranched Polyester Hydrogels with Controlled Drug Release and Cell Adhesion Properties, Biomacromolecules, 2013, 14(5), 1299-1310.

35 A. Zamboulis, E. A. Nakiou, E. Christodoulou, D. N. Bikiaris, E. Kontonasaki, L. Liverani and A. R. Boccaccini, Polyglycerol Hyperbranched Polyesters: Synthesis, Properties and Pharmaceutical and Biomedical Applications, Int. J. Mol. Sci., 2019, 20(24), 6210.

36 T. Gurunathan, S. Mohanty and S. K. Nayak, Hyperbranched Polymers for Coating Applications: A Review, Polym.-Plast. Technol. Eng., 2016, 55(1), 92-117.

37 S. Ma, J. Qian, Q. Zhuang, X. Li, W. Kou and S. Peng, Synthesis and application of water-soluble hyperbranched polyester modified by trimellitic anhydride, J. Macromol. Sci., Part A: Pure Appl.Chem., 2018, 55(5), 414-421.

$38 \mathrm{X}$. Zhang, Modifications and applications of hyperbranched aliphatic polyesters based on dimethylolpropionic acid, Polym. Int., 2011, 60(2), 153-166.

39 L.-M. Tang, T. Qiu, X.-L. Tuo, X.-L. Zhang and D.-S. Liu, Synthesis, Morphology and Application of Alkylaryl Hyperbranched Polyesters, Polym. J., 2002, 34(3), 112-116.

40 M. Johansson, E. Malmström, A. Jansson and A. Hult, Novel concept for low temperature curing powder coatings based on hyperbranched polyesters, J. Coat. Technol., 2000, 72(906), 49-54.

41 D. Schmaljohann, B. I. Voit, J. F. G. A. Jansen, P. Hendriks and J. A. Loontjens, New coating systems based on vinyl ether- and oxetane-modified hyperbranched polyesters, Macromol. Mater. Eng., 2000, 275(1), 31-41.

42 Q. Wan, S. R. Schricker and B. M. Culbertson, Methacryloyl derivitized hyperbranched polyester. 1. Synthesis, characterization, and copolymerization, J. Macromol. Sci., Part A: Pure Appl.Chem., 2000, 37(11), 1301-1315.

43 G. Belge, D. Beyerlein, C. Betsch, K.-J. Eichhorn, G. Gauglitz, K. Grundke and B. Voit, Suitability of hyperbranched polyester for sensoric applications - investigation with reflectometric interference spectroscopy, Anal. Bioanal. Chem., 2002, 374(3), 403-411.

44 A. Gandini and T. M. Lacerda, From monomers to polymers from renewable resources: Recent advances, Prog. Polym. Sci., 2015, 48, 1-39.

45 T. T. Hsieh, C. Tiu and G. P. Simon, Melt rheology of aliphatic hyperbranched polyesters with various molecular weights, Polymer, 2001, 42(5), 1931-1939.

46 T.-T. Hsieh, C. Tiu and G. P. Simon, Rheological behaviour of polymer blends containing only hyperbranched polyesters of varying generation number, Polymer, 2001, 42(18), 7635-7638.

47 C. M. Nunez, B.-S. Chiou, A. L. Andrady and S. A. Khan, Solution Rheology of Hyperbranched Polyesters and Their Blends with Linear Polymers, Macromolecules, 2000, 33(5), 1720-1726.

48 F. H. Isikgor and C. R. Becer, Lignocellulosic biomass: a sustainable platform for the production of bio-based chemicals and polymers, Polym. Chem., 2015, 6(25), 44974559. 
49 X.-J. Ji, H. Huang, Z.-K. Nie, L. Qu, Q. Xu and G. T. Tsao, in Fuels and Chemicals from Hemicellulose Sugars. In Biotechnology in China III: Biofuels and Bioenergy, ed. F.-W. Bai, C.-G. Liu, H. Huang and G. T. Tsao, Springer Berlin Heidelberg, Berlin, Heidelberg, 2012, pp. 199-224.

$50 \mathrm{~J}$. Ohyama and A. Satsuma, Reductive Conversion of 5-Hydroxymethylfurfural in Aqueous Solutions by Furan Ring Opening and Rearrangement, in Production of Biofuels and Chemicals with Bifunctional Catalysts, ed. Z. Fang, R. L. Smith Jr and H. Li, Springer Singapore, Singapore, 2017, pp. 159-185.

51 A. Lachke, Biofuel fromD-xylose-The second most abundant sugar, Resonance, 2002, 7(5), 50-58.

52 J. Han, A bio-based 'green' process for catalytic adipic acid production from lignocellulosic biomass using cellulose and hemicellulose derived $\gamma$-valerolactone, Energy Convers. Manage., 2016, 129, 75-80.

53 H. Choudhary, S. Nishimura and K. Ebitani, Metal-free oxidative synthesis of succinic acid from biomass-derived furan compounds using a solid acid catalyst with hydrogen peroxide, Appl. Catal., A, 2013, 458, 55-62.

54 A. Köckritz and A. Martin, Synthesis of azelaic acid from vegetable oil-based feedstocks, Eur. J. Lipid Sci. Technol., 2011, 113(1), 83-91.

55 A. Soutelo-Maria, J.-L. Dubois, J.-L. Couturier and G. Cravotto, Oxidative Cleavage of Fatty Acid Derivatives for Monomer Synthesis, Catalysts, 2018, 8(10), 464.

56 P. J. Flory, Fundamental principles of condensation polymerization, Chem. Rev., 1946, 39(1), 137-197.

57 P. R. M. Dvornic, J. Hu, D. J. Meier, R. M. Nowak and P. L. Parham, Hyperbranched polyureas, polyurethanes, polyamidoamines, polyamides and polyesters, US Pat., US6534600B2, 2003.

58 J.-F. Stumbé and B. Bruchmann, Hyperbranched Polyesters Based on Adipic Acid and Glycerol, Macromol. Rapid Commun., 2004, 25(9), 921-924.

59 P. B. M. Smith, B. A. Howell and C. Zhang, Sustained release composition using biobased biodegradable hyperbranched polyesters, WO2015130602A2, 2015.

60 N. Xu, E. J. Stark, P. R. Dvornic, D. J. Meier, J. Hu and C. Hartmann-Thompson, Hyperbranched Polycarbosiloxanes and Polysiloxanes with Octafunctional Polyhedral Oligomeric Silsesquioxane (POSS) Branch Points, Macromolecules, 2012, 45(11), 4730-4739.

61 P. R. Dvornic and D. J. Meier, Hyperbranched SiliconContaining Polymers via Bimolecular Non-linear Polymerization, in Silicon-Containing Dendritic Polymers, ed. P. R. Dvornic and M. J. Owen, Springer Netherlands, Dordrecht, 2009, pp. 401-419.

62 J. Hu, P. I. Carver, D. J. Meier, E. J. Stark, N. Xu, T. Zhang, C. Hartmann-Thompson and P. R. Dvornic, Hyperbranched polycarbosiloxanes and polycarbosilanes via bimolecular non-linear hydrosilylation polymerization, Polymer, 2012, 53(24), 5459-5468.

63 C. W. Macosko and D. R. Miller, A New Derivation of Average Molecular Weights of Nonlinear Polymers, Macromolecules, 1976, 9(2), 199-206.
64 C. Gao and D. Yan, Hyperbranched polymers: from synthesis to applications, Prog. Polym. Sci., 2004, 29(3), 183-275.

65 S. R. Marinović, Synthesis and Applications of Hyperbranched Polyesters: A Review, in Hyperbranched Polymers: Properties, Synthesis and Applications, ed. C. R. Lewis, Nova Science Publishers, Inc., 2017, pp. 65-79.

66 R. K. Roy and S. Ramakrishnan, Control of Molecular Weight and Polydispersity of Hyperbranched Polymers Using a Reactive B3 Core: A Single-Step Route to Orthogonally Functionalizable Hyperbranched Polymers, Macromolecules, 2011, 44(21), 8398-8406.

67 D. P. Bernal, L. Bedrossian, K. Collins and E. Fossum, Effect of Core Reactivity on the Molecular Weight, Polydispersity, and Degree of Branching of Hyperbranched Poly(arylene ether phosphine oxide)s, Macromolecules, 2003, 36(2), 333-338.

68 B. Nie, J. Stutzman and A. Xie, A vibrational spectral maker for probing the hydrogen-bonding status of protonated Asp and Glu residues, Biophys. J., 2005, 88(4), 2833-2847.

69 B. A. J. Noordover, R. Duchateau, R. A. T. M. van Benthem, W. Ming and C. E. Koning, Enhancing the Functionality of Biobased Polyester Coating Resins through Modification with Citric Acid, Biomacromolecules, 2007, 8(12), 3860-3870.

70 M. W. Khemici, N. D. A. Gourari and M. Bendaoud, Contribution to the Study of the Enthalpy Relaxation of Polyesters by DSC Experiments, Int. J. Polym. Anal. Charact., 2012, 17(5), 358-370.

71 X. Kong, H. Qi and J. M. Curtis, Synthesis and characterization of high-molecular weight aliphatic polyesters from monomers derived from renewable resources, J. Appl. Polym. Sci., 2014, 131(15), 40579.

72 M. S. Nikolic and J. Djonlagic, Synthesis and characterization of biodegradable poly(butylene succinate-co-butylene adipate)s, Polym. Degrad. Stab., 2001, 74(2), 263-270.

73 E. M. Woo, Y.-H. Chou, W.-J. Chiang, I. T. Chen, I. H. Huang and N.-T. Kuo, Amorphous phase behavior and crystalline morphology in blends of poly(vinyl methyl ether) with isomeric polyesters: poly(hexamethylene adipate) and poly( $(\varepsilon-$ caprolactone), Polym. J., 2010, 42(5), 391-400.

74 Z. Bai, Y. Liu, T. Su and Z. Wang, Effect of Hydroxyl Monomers on the Enzymatic Degradation of Poly(ethylene succinate), Poly(butylene succinate), and Poly(hexylene succinate), Polymers, 2018, 10(1), 90.

75 D. G. Barrett and M. N. Yousaf, Poly(triol $\alpha$-ketoglutarate) as Biodegradable, Chemoselective, and Mechanically Tunable Elastomers, Macromolecules, 2008, 41(17), 63476352.

76 M. Kwiecień, I. Kwiecień, I. Radecka, V. Kannappan, M. R. Morris and G. Adamus, Biocompatible terpolyesters containing polyhydroxyalkanoate and sebacic acid structural segments - synthesis and characterization, RSC Adv., 2017, 7(33), 20469-20479.

77 S.-W. Kuo, H. Xu, C.-F. Huang and F.-C. Chang, Significant glass-transition-temperature increase through hydrogenbonded copolymers, J. Polym. Sci., Part B: Polym. Phys., 2002, 40(19), 2313-2323. 